\title{
NIH urged to address chimp care 'crisis'
}

[WASHINGTON] A \$7 million-a-year Chimpanzee Management Program — or ChiMP - should be established at the office of the director of the National Institutes of Health (NIH) to provide lifelong care for 1,000 research chimps in the United States. So concludes a report from the National Academy of Sciences published this week.

Dani Bolognesi, director of the Duke Center for AIDS Research in North Carolina, and chair of the panel that produced the report, says that central control would deal with a crisis in the management of the chimpanzees, many of which are no longer needed for research. The cost of the programme would be similar to the costs at present borne by various government agencies responsible for the chimps, Bolognesi says, and should not come out of the NIH biomedical research budget.

The report rejects the culling of the chimps. But a minority report by panel member Sarah Williams-Blangero, of the Southwest Foundation for Biomedical Research at San Antonio, Texas, says that culling would maximize the quality of life of the remaining population, and should be considered.

The study also rejects demands from animal rights groups that the government should stop using the chimps for research, and should help to pay for sanctuaries where they could retire. Bolognesi says that chimps managed under the new programme could retire later to such sanctuaries if and when they are established. The panel proposes a

four-year moratorium on chimp breeding, to be reviewed annually.

Chimpanzee care is a hot issue in the United States because there is a surplus of the animals, worsened in recent years by an NIH-sponsored breeding programme. They are expensive to care for, and the public will not accept that they be neglected or killed. The normal life span of a chimpanzee is $40-45$ years.

The 1,000 or so chimps owned and supported by government agencies — including the National Cancer Institute, the Centers for Disease Control and the US Air Forceare kept at six centres across the country, while another 500 are in private facilities.

Some of the chimps have AIDS or hepatitis and are kept in solitary confinement. But Bolognesi says that their overall plight is not as bad as he had feared at the outset of the study: "There are a few problems but by and large they are fairly comfortable," he says. But, as costs go up and reimbursement from the federal government goes down, "the facilities are going to go bankrupt", he says. "They are trying to get rid of the chimps as fast as they can."

Bolognesi predicts that good, stable management by ChiMP could revive flagging research interest in the animals, lifting the threat that anyone who makes use of the animals will incur lifetime care costs.

The report is unlikely to mollify animal activist groups, which have demanded that NIH set aside up to $\$ 100$ million to help pay for retirement sanctuaries for the chim-

\section{Small increase planned in German budget}

[MUNICH] Jürgen Rüttgers, Germany's minister for education and research, may be about to resurrect his reputation as 'minister for the future'. Last week, the German cabinet approved a funding increase of just under 1 per cent for education and research next year - almost twice the increase for the budget as a whole.

The research budget will now total nearly DM15 billion (US $\$ 8.5$ billion). Rüttgers says that, if the funding increase is approved by parliament, the extra money will be allocated to previously established research priorities, including biotechnology, molecular medicine, information technology and environmental technology.

He will keep promises to maintain the level of special funding to support the development of research infrastructure in east Germany, and to increase by 5 per cent the budgets of the Max Planck Society and the Deutsche Forschungsgemeinschaft, Germany's university grants council. The budget of the Fraunhofer Society, which runs 47 applied research institutes, will rise by 3 per cent.

Because the relatively small increase in budget will not cover all these plans, Rüttgers has also proposed cuts. Most significant is his decision to reduce spending on nuclear safety, despite Germany's proximity to reactors in central and eastern Europe whose safety is uncertain.

Under the budget proposal, funding for safety research for nuclear power stations would be cut by 3.6 per cent, and for decommissioning nuclear power stations by around 6 per cent.

Rüttgers is proposing to cut by 11 per cent Germany's contributions to the Viennabased International Atomic Energy Agency. This will probably affect the agency's voluntary technical assistance fund, which supports a wide range of research, from reactor safety technology to the medical consequences of radiation exposure. The combined cuts will release just over DM50 million.

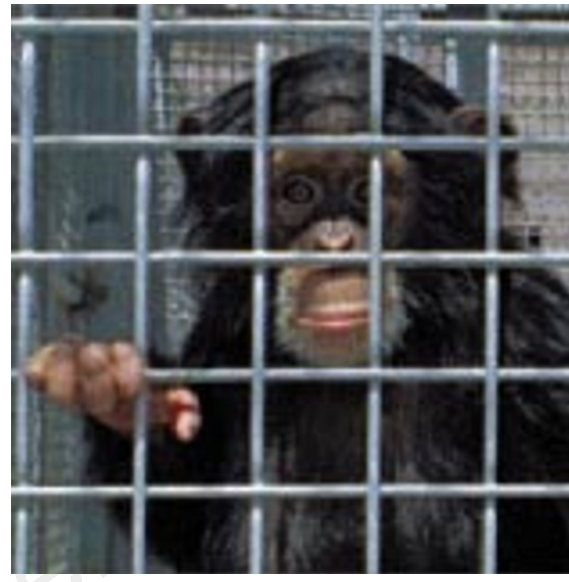

Short sighted: sponsored breeding programmes have created a surplus of research chimpanzees.

panzees (see Nature 381, 722; 1996). The NIH may be reluctant to accept responsibility for all the chimps - especially the director's office, which has been seeking to pare down its functions.

And some observers question whether Congress will support a programme intended expressly to look after chimps. "It would be far more compelling if we attached this to some human benefit rather than simply establishing a chimp welfare program," says Joe Erwin, past president of the American Society of Primatologists.

Some scientists are concerned about the lack of logic in society treating chimps better than it does other research animals - or disadvantaged humans, for that matter. "We can't tell you that the chimpanzee is the only animal that should be accorded this privilege," says Bolognesi. "But we do have a crisis with the chimps right now."

The academy report says that the ChiMP programme would operate under the supervision of an independent board of scientists and other interested parties. It says that its proposals could win the approval of scientists, the public and members of Congress, but that "NIH must work hard to achieve that breadth of approval".

Criticism of the care of chimpanzees in the United States has focused on the treatment of 600 or so animals that are held by the Coulston Foundation in New Mexico, of which 200 are paid for by the government. An official at the academy says that the study had received "very little information" about the animals held by Coulston, which has been lambasted by animal rights groups for its standards of care.

The US Air Force has been trying to dispose of its 135 chimps for many years. But the budget system makes it difficult to transfer money from the air force to, for example, the NIH for the future care of the animals.

ColinMacilwain 